\title{
Effect of adding growth factors during in vitro maturation on the developmental potentials of ewe oocytes selected by brilliant cresyl blue staining
}

\author{
Mohamed Fathi' ${ }^{1}$ and Amr F. Elkarmoty²
}

1. Department of Theriogenology, Faculty of Veterinary Medicine, Cairo University, Egypt; 2. Department of Anatomy and Embryology, Faculty of Veterinary Medicine, Cairo University, Egypt.

Corresponding author: Amr F. Elkarmoty, e-mail: amr.elkarmoty@yahoo.com

Co-author: MF: mido2022@yahoo.com

Received: 12-09-2020, Accepted: 04-01-2021, Published online: 22-02-2021

doi: www.doi.org/10.14202/vetworld.2021.452-456 How to cite this article: Fathi M, Elkarmoty AF (2021) Effect of adding growth factors during in vitro maturation on the developmental potentials of ewe oocytes selected by brilliant cresyl blue staining, Veterinary World, 14(2): 452-456.

\begin{abstract}
Aim: Several factors had been concerned with the developmental competence of the sheep oocyte. This study aims to investigate the effect of adding growth factors (insulin-like growth factor 1 [IGF-1] and epidermal growth factor [EGF]) in the maturation medium of ewe oocytes selected based on brilliant cresyl blue (BCB) screening on in vitro maturation (IVM), fertilization, and pre-implantation embryo development.

Materials and Methods: Cumulus-oocyte complexes (COCs) were obtained from the ovaries of slaughtered ewes by either aspiration or slicing techniques. COCs were in vitro matured in a medium containing IGF-1 and EGF (control group). For $\mathrm{BCB}$ screening, oocytes were stained and divided into $\mathrm{BCB}+$ oocytes that matured in the same maturation conditions without adding growth factors (Group 2) or in the presence of growth factors (Group 3), and $\mathrm{BCB}-$ oocytes that matured in medium without growth factors (Group 4) or with growth factors (Group 5).
\end{abstract}

Results: The supplementation of the maturation medium with growth factors during IVM of ( $\mathrm{BCB}+$ ) oocytes resulted in a significant increase in nuclear maturation rate $(90.9 \%)$, fertilization rate $(75.6 \%)$, and embryo developmental rates $(60.0 \%$, $46.7 \%$, and $33.3 \%$ for cleavage, morula, and blastocyst, respectively).

Conclusion: Culturing BCB+ oocytes in a maturation medium containing both EGF and IGF-1 showed a significant improvement in nuclear maturation, fertilization, and pre-implantation embryo development in vitro.

Keywords: brilliant cresyl blue, embryo development, growth factors, In vitro fertilization, sheep.

\section{Introduction}

Assisted reproductive technologies have been reported as one of the major tools for increasing productivity in the livestock industry. In this domain, embryo transfer, in vitro fertilization, embryo cryopreservation, sex determination, and cloning in the small ruminant, such as sheep, had lower progress, the pregnancy rates remain low, and with high early embryonic mortalities [1]. The success of an in vitro fertilization protocol depends on the ability of the selected oocyte to resume meiosis and develop to blastocyst after fertilization [2]. Several factors have been concerned with the developmental competence of the oocyte, including the size of the follicle [3], hormonal stimulation [2], and maturation conditions [4]. In vitro maturation (IVM) of sheep oocytes followed by fertilization using capacitated spermatozoa and culturing the presumptive zygotes in vitro has been established in sheep [5] and also in goat [6].

Copyright: Fathi and Elkarmoty. Open Access. This article is distributed under the terms of the Creative Commons Attribution 4.0 International License (http://creativecommons.org/licenses/ by/4.0/), which permits unrestricted use, distribution, and reproduction in any medium, provided you give appropriate credit to the original author(s) and the source, provide a link to the Creative Commons license, and indicate if changes were made. The Creative Commons Public Domain Dedication waiver (http:// creativecommons.org/publicdomain/zero/1.0/) applies to the data made available in this article, unless otherwise stated.
Brilliant cresyl blue (BCB) has been reported as a successful non-invasive method in selecting more competent oocytes that develop to the blastocyst stage in different species as cow [7] and goats [8]. Recently, BCB screening studies on human oocytes were reported [9]. Depending on the activity of glucose-6-phosphate dehydrogenase (G6PDH) in the oocytes, $\mathrm{BCB}$ can differentiate between more competent oocytes that have lower G6PDH activity and showing blue coloration in their cytoplasm $(\mathrm{BCB}+)$ and less competent oocytes that have higher G6PDH activity, which have a reduced blue color to a colorless cytoplasm (BCB-) [9]. Media containing growth factors such as insulin-like growth factor 1 (IGF-1) or epidermal growth factor (EGF) have been reported to improve oocyte maturation, fertilization, and blastocyst development in many species, including sheep [10]. EGF triggers its receptors on the cell surface for proliferation, transphosphorylation of tyrosine residues, and resumption of meiosis in sheep oocytes [11], while IGF-1 acts as an amplifier to the action of follicle-stimulating hormone (FSH) [12].

This study aimed to investigate the developmental potentials of sheep oocytes selected using BCB with growth factors (IGF-1 and EGF) in a maturation 
medium on nuclear maturation, fertilization, and the pre-implantation embryo development in vitro.

\section{Materials and Methods \\ Ethical approval}

The study was approved by the Ethics Committee of Animal Reproduction Research Institute, Giza, Egypt.

\section{Study period and location}

Ovaries were collected from a local slaughterhouse (Cairo, Egypt) from March 2016 to February 2017. The study was conducted at Laboratory of Animal Reproduction Research Institute, Giza, Egypt.

\section{Chemicals and reagents}

All chemicals, media, and media constituents were purchased from Sigma-Aldrich. The practical work was done at Reproduction Research Institute, Department of Embryo Transfer and Artificial Insemination, Giza, Egypt.

\section{Oocytes recovery}

A total of 370 ewe ovaries (ranging from 2 to 4 years old) were collected $30 \mathrm{~min}$ post-slaughter and placed in a thermos flask containing pre-warmed saline $\left(30^{\circ} \mathrm{C}\right)$ fortified with $100 \mathrm{ug} / \mathrm{mL}$ of streptomycin.

The oocytes were recovered by aspiration of 2-6 mm follicles with a $20 \mathrm{~g}$ needle and a $3 \mathrm{~mL}$ syringe [13], using the slicing technique previously mentioned by El-Harairy et al. [14]. Oocytes with homogenous ooplasm and multiple layers of cumulus cells were selected by stereomicroscope.

\section{Oocytes staining by $\mathrm{BCB}$}

The recovered oocytes were stained using $\mathrm{BCB}$ as mentioned by Alm et al. [15]. Briefly, cumulus-oocyte complexes (COCs) were washed several times in a Dulbecco's phosphate buffer saline modified by $0.4 \%$ bovine serum albumin, then exposed to $26 \mu \mathrm{M}$ $\mathrm{BCB}$ diluted in modified PBS for $90 \mathrm{~min}$ at $38^{\circ} \mathrm{C}$ in $5 \% \mathrm{CO}_{2}$ humidified atmosphere. COCs were transferred to the modified PBS for washing followed by examination under stereomicroscope. Oocytes with any extent of blue coloration in their cytoplasm were recorded as $\mathrm{BCB}+$, while those without blue color in the cytoplasm were recorded as $\mathrm{BCB}-$.

\section{In vitro oocytes maturation}

The oocytes were washed 3 times in a washing medium (tissue culture medium [TCM]-199 supplemented with $10 \%$ fetal calf serum [FCS]). For maturation, the maturation medium (TCM-199 supplemented with $10 \% \mathrm{FCS}, 0.8 \mathrm{mM}$ sodium pyruvate, $2 \mathrm{mM}$ L-glutamine, $10 \mu \mathrm{g}$ FSH, $10 \mu \mathrm{g} \mathrm{LH}, 50 \mathrm{ng}$ IGF-1, $50 \mathrm{ng} \mathrm{EGF}$, and $50 \mu \mathrm{g} / \mathrm{mL}$ gentamycin) was the control (Group 1). Groups of 10-15 COCs were placed in a $100 \mu \mathrm{L}$ droplet of IVM medium covered with mineral oil previously sterilized by filtration using a 50 Millipore filter membrane. The oocytes were incubated at $39^{\circ} \mathrm{C}$ in high humidity with $5 \% \mathrm{CO}_{2}$ for $24 \mathrm{~h}$. At the end of the maturation time, the oocytes were examined for signs of nuclear maturation after staining with the aceto-orcein stain as described by Fathi and El-Shahat [16]. For other treatment groups based on BCB screening, BCB+ oocytes were matured either in the same maturation medium without growth factors (IGF-1 and EGF) (Group 2) or with growth factors (IGF-1 and EGF) (Group 3) in the same maturation conditions. For $\mathrm{BCB}-$ oocytes, the oocytes were matured either in the same maturation medium without growth factors (IGF-1 and EGF) (Group 4) or with growth factors (IGF-1 and EGF) (Group 5) in the same maturation conditions.

\section{Sperm preparation}

Fresh semen of frozen-thawed ram (aged 3 years old) was used for in vitro fertilization of the matured oocytes. Motile sperms were obtained using the swim-up technique as described by Fathim et al. [17]. Two $0.25 \mathrm{~mL}$ straws (previously frozen and tested at the reproduction research institute) were thawed in a water bath $\left(38^{\circ} \mathrm{C}\right.$ for $\left.15 \mathrm{~s}\right)$ and emptied in a $15 \mathrm{~mL}$ centrifuge tube, modified Tyrode's albumin lactate pyruvate (TALP) medium with Hepes modification was added to the centrifuge tube and allowed to centrifuge at $500 \times \mathrm{g}$. After discarding the supernatant, the sperm pellet was resuspended in a $2 \mathrm{~mL}$ TALP medium supplemented with $5 \mathrm{~mm}$ caffeine and incubated for $30 \mathrm{~min}$ at $39^{\circ} \mathrm{C}$ in a $\mathrm{CO}_{2}$ incubator. After swimming up, the motile sperm was picked up for oocyte insemination at a final concentration of $2 \times 10^{6} / \mathrm{mL}$.

\section{In vitro insemination of the matured oocytes}

After $24 \mathrm{~h}$ of maturation, IVM oocytes were washed several times with pre-incubated fertilization medium (F-TALP) supplemented with 10\% estrous ewe serum previously collected from estrous ewes.

Groups of 10-15 oocytes were coincubated with spermatozoa in a $100 \mu \mathrm{L}$ fertilization medium for 18-24 h.

Fertilization events were determined based on the appearance of normal or enlarged sperm head in the ooplasm and presence of male and female pronuclei after staining with the aceto-orcein stain as described by Mohamed et al. [18].

\section{In vitro culture}

After 18-24 $\mathrm{h}$ of coincubation of sperm with oocytes in vitro, the presumptive zygotes were washed several times in pre-incubated culture media (synthetic oviductal fluid medium supplemented with BSA) to remove any adherent sperm.

Groups of 5-10 zygotes were incubated in a $100 \mu \mathrm{L}$ droplet of culture medium under mineral oil at $39^{\circ} \mathrm{C}$ in a $\mathrm{CO}_{2}$ incubator in a highly humid air until day 6 (day $0=$ day of insemination).

The cultured medium was refreshed by replacing half of the original medium with a similar volume of the pre-incubated fresh medium.

The cleaved embryos (2-16 cells) were evaluated 24-72 $\mathrm{h}$ after insemination, and development to morula and blastocyst stages was recorded further. 


\section{Statistical analysis}

Data were accessible as percentages; at least three replicates were conducted for each experimental group. Results of each group were compared with the other group by a Chi-squared test using GraphPad Prism 5 software (https://www.graphpad.com/scientific-software/prism/). Significance was recorded at $\mathrm{p}<0.05$.

\section{Results}

\section{Effect of adding growth factors during the IVM of BCB-selected oocytes}

Growth factors supplementation during the IVM of $\mathrm{BCB}+$ oocytes showed a significant $(\mathrm{p}<0.05)$ increase in maturation rate $(90.9 \%)$ than $\mathrm{BCB}+$ oocytes without growth factors $(74.4 \%)$ and the control $(77.8 \%)$. The lowest values were obtained in BCB- oocytes either matured in the presence or absence of growth factors (68.6\% and 59.8\%, respectively), as shown in Table- 1 .

Effect of growth factor supplementation during the IVM of BCB-selected oocytes on fertilization rates

The fertilization rate of positively selected oocytes based on the BCB screening with the addition of growth factors during the IVM showed the highest value $(75.6 \%)$ than the other groups. There was no significant difference observed between $\mathrm{BCB}+$ oocytes without growth factors during the IVM and the control group in terms of fertilization $(60.7 \%$ and $62.3 \%$, respectively). The lowest values of fertilization rates were found in $\mathrm{BCB}-$ oocytes either with or without growth factors $(51.3 \%$ and $48.7 \%$, respectively), as shown in Table-2.

\section{Effect of growth factors supplementation during the IVM of BCB-selected oocytes on pre-implantation embryo development}

The percentages of cleavage, morula, and blastocyst obtained from the IVM of $\mathrm{BCB}+$ oocytes with growth factors followed by fertilization $(60.0 \%$, $46.7 \%$, and $33.3 \%)$ were significantly $(\mathrm{p}<0.05)$ higher than those obtained from the IVM of $\mathrm{BCB}+$ oocytes without growth factors and the control $(41.9 \%, 29.1 \%$, and $18.6 \% ; 44.3 \%, 31.8 \%$, and $20.5 \%$, respectively). Interestingly, all of the previously mentioned values were significantly $(\mathrm{p}<0.05)$ higher than those recorded using BCB- oocytes with or without growth factors addition $(31.9 \%, 19.1 \%$, and $9.6 \% ; 28.4 \%, 16.8 \%$, and $7.4 \%$, respectively), as shown in Table-3.

\section{Discussion}

Oocyte selection based on the BCB screening has been previously established in other species at different concentrations, such as $26 \mu \mathrm{m}$ for cow [19] and goat [20], while $13 \mu \mathrm{m}$ of BCB was the concentration of choice in porcine oocytes [21].

Adding growth factors to the maturation medium was demonstrated by Guler et al. [11] who found that EGF promotes cumulus expansion and chromatin condensation, while IGF1 stimulates the proliferation of granulosa cells due to the presence of IGF-1 receptors on its plasma membrane.
Table-1: Effect of growth factors addition during IVM on maturation rate of $\mathrm{BCB}$ selected oocytes.

\begin{tabular}{|c|c|c|}
\hline \multirow[t]{2}{*}{ Groups } & \multirow[t]{2}{*}{ No. of oocytes } & \multirow{2}{*}{$\begin{array}{c}\begin{array}{c}\text { Oocytes } \\
\text { maturation }\end{array} \\
\text { No, (\%) }\end{array}$} \\
\hline & & \\
\hline Control & 81 & $63(77.8)^{\mathrm{b}}$ \\
\hline bcb+oocytes & 82 & $61(74.4)^{b}$ \\
\hline $\begin{array}{l}\mathrm{BCB}+0 \text { ocytes with growth } \\
\text { factors (IGF-1 and EGF) }\end{array}$ & 98 & $89(90.9)^{a}$ \\
\hline BCB- oocytes & 92 & $55(59.8)^{c}$ \\
\hline $\begin{array}{l}\text { Bcb- oocytes with growth } \\
\text { factors (IGF-1 and EGF) }\end{array}$ & 86 & $59(68.6)^{b c}$ \\
\hline
\end{tabular}

Values with different superscripts in the same column are significantly different at $(\mathrm{p}<0.05), \mathrm{IVM}=$ In vitro maturation, $\mathrm{BCB}=$ Brilliant cresyl blue, $\mathrm{IGF}=$ Insulin-like growth factor, EGF=Epidermal growth factor

Table-2: Effect of addition of growth factors during IVM of $\mathrm{BCB}$ selected oocytes on the fertilization rate.

\begin{tabular}{lcc}
\hline Groups & $\begin{array}{c}\text { No. of } \\
\text { inseminated } \\
\text { oocytes }\end{array}$ & $\begin{array}{c}\text { Fertilization } \\
\text { rates }\end{array}$ \\
\cline { 3 - 3 } & 77 & No, (\%) \\
\hline Control & 84 & $51(62.3)^{\mathrm{b}}$ \\
Bcb+oocytes & 82 & $62(75.7)^{\mathrm{b}}$ \\
Bcb+with growth & 78 & $38(48.7)^{\mathrm{c}}$ \\
factors (IGF-1 and EGF) & 80 & $41(51.3)^{\mathrm{c}}$ \\
Bcb- oocytes & & \\
Bcb- oocytes with growth & & \\
factors (IGF-1 and EGF) & & \\
\hline
\end{tabular}

Values with different superscripts in the same column are significantly different at $(\mathrm{p}<0.05)$. IVM $=$ In vitro maturation, $\mathrm{BCB}=$ Brilliant cresyl blue, $\mathrm{IGF}=$ Insulin-like growth factor, EGF=Epidermal growth factor

The current work revealed that the supplementation of the maturation medium of $\mathrm{BCB}+$ oocytes with both EGF and IGF-1 resulted in a significant increase in the maturation, fertilization, and pre-implantation embryo developmental rates than the other tested groups.

Similarly, Wang et al. [22] demonstrated that the BCB screening test allowed a selection of large oocytes with higher mitochondrial activity, allowing higher maturation, fertilization, and a significant increase in the percentage of embryo developmental rates in sheep. Silva et al. [23] added that the developmental potentials of the bovine oocytes selected based ion BCB staining showed a significant increase in the percentage of morula and blastocyst developments than those selected based on morphological characteristics. On the contrary, $\mathrm{BCB}-$ oocytes were less competent due to the delayed replication of the mitochondrial DNA; therefore, the oocytes failed to behave normally [24].

Concerning with growth factors supplementation, Dhanraj and Purohit [25] found that adding $50 \mathrm{ng}$ of EGF to the maturation medium of goat oocytes resulted in significantly $(\mathrm{p}<0.05)$ higher maturation rate $(52.35 \%)$ than the control $(34.07 \%)$ and also significantly $(\mathrm{p}<0.05)$ increased the fertilization rate $(28.27 \%)$ than the control $(9.83 \%)$. Nearly similar to our results, Dinesh and Purohit [26] found that using 
Table-3: Effect of growth factors addition during IVM of BCB selected oocytes on the percentages of cleavage, morula and blastocyst development.

\begin{tabular}{lcccc}
\hline Groups & $\begin{array}{c}\text { No. of inseminated } \\
\text { oocytes }\end{array}$ & Cleavage (2-16 cell stage) & Morula & Blastocyst \\
\cline { 3 - 5 } & 88 & No. (\%) & No. (\%) & No. (\%) \\
\hline Control & 86 & $39(44.3)^{\mathrm{b}}$ & $28(31.8)^{\mathrm{b}}$ & $18(20.5)^{\mathrm{b}}$ \\
Bcb+oocytes & 105 & $36(41.9)^{\mathrm{b}}$ & $25(29.1)^{\mathrm{b}}$ & $16(18.6)^{\mathrm{b}}$ \\
Bcb+oocytes with growth & 95 & $63(60.0)^{\mathrm{a}}$ & $49(46.7)^{\mathrm{a}}$ & $35(33.3)^{\mathrm{a}}$ \\
factors (IGF-1 and EGF) & 94 & $27(28.4)^{\mathrm{c}}$ & $16(16.8)^{\mathrm{c}}$ & $7(7.4)^{\mathrm{c}}$ \\
$\begin{array}{l}\text { Bcb- oocytes } \\
\text { Bcb- oocytes with growth }\end{array}$ & & $30(31.9)^{\mathrm{c}}$ & $18(19.1)^{\mathrm{c}}$ & $9(9.6)^{\mathrm{c}}$ \\
factors (IGF-1 and EGF) & & & & \\
\hline
\end{tabular}

Values with different superscripts in the same column are significantly different at $(\mathrm{p}<0.05)$. IVM=In vitro maturation, $\mathrm{BCB}=$ Brilliant cresyl blue, IGF=Insulin-like growth factor, $E G F=$ Epidermal growth factor

both EGF and IGF-1 on the maturation medium of buffalo oocytes resulted in a higher maturation rate $(83.52 \%)$ than using IGF-1 alone $(67.08 \%)$ and EGF alone $(63.64 \%)$ and significantly $(\mathrm{p}<0.05)$ higher than the control $(46.30 \%)$, and a higher fertilization rate $(48.62 \%)$ than IGF-1 alone $(36.36 \%)$ and significantly $(\mathrm{p}<0.05)$ higher than the control $(15.00 \%)$. Moreover, Pawshe et al. [27] reported that the percentage of cleavage and blastocyst development using both EGF and IGF-1 (66.0\% and 21.2\%) was significantly $(\mathrm{p}<0.05)$ higher than the control group $(38.5 \%$ and 14.8\%). Lonergan et al., Harvey and Kaye, Lee and Fukui, and Simmen et al. [28-31] suggested that the increased cleavage, morula, and blastocyst development may be attributed to the positive effect of both EGF and IGF-1 on oocytes maturation. Similarly, Down et al. [32] reported that EGF helps in breaking the germinal vesicle and enhances the maturation rate of denuded oocytes to the MII stage.

\section{Conclusion}

The current study demonstrated the usefulness of the supplementation of a maturation medium with both $50 \mathrm{ng}$ of EGF and IGF-1 during the IVM of sheep oocytes selected by BCB staining on the proportion of in vitro nuclear maturation, fertilization, and subsequent sheep embryos development pre-implantation.

\section{Authors' Contributions}

MF: Designed the paper, data collection, made the practical part, analyzed the data, and wrote the manuscript. AFE: Designed the paper, collection of ovaries, follow-up embryonic developmental stages, and revision of the paper. Both authors have read and approved the final manuscript.

\section{Acknowledgments}

The authors want to express deep gratitude to the staff members of Reproduction Research Institute for their support and help while applying the practical part of this work. The authors did not receive any funds for this study.

\section{Competing Interests} interests.

The authors declare that they have no competing

\section{Publisher's Note}

Veterinary World remains neutral with regard to jurisdictional claims in published institutional affiliation.

\section{References}

1. Granleese, T., Clark, S.A., Swan, A.A. and Van der Werf, J.H.J. (2015) Increased genetic gains in sheep, beef and dairy breeding programs from using female reproductive technologies combined with optimal contribution selection and genomic breeding values. Genet. Sel. Evol., 47(1): 70 .

2. Matsubara, S., Shiraishi, A., Osugi, T., Kawada, T. and Satake, H. (2019) The regulation of oocyte maturation and ovulation in the closest sister group of vertebrates. Elife, 8: e49062.

3. Romaguera, R., Moll, X., Morato, R., Roura, M., Palomo, M.J., Catala, M.G., Jimenez-Macedo, A.R., Hammami, S., Izquierdo, D., Mogas, T. and Paramio, M.T. (2011) Prepubertal goat oocytes from large follicles result in similar blastocyst production and embryo ploidy than those from adult goats. Theriogenology, 76(1): 1-11.

4. Moawad, A.R., Tan, S.L. and Taketo, T. (2017) Beneficial effects of glutathione supplementation during vitrification of mouse oocytes at the germinal vesicle stage on their preimplantation development following maturation and fertilization in vitro. Cryobiology, 76(June): 98-103.

5. Paramio, M.T. and Izquierdo, D. (2016) Recent advances in in vitro embryo production in small ruminants. Theriogenology, 86(1): 152-159

6. Menchaca, A., Barrera, N., Dos Santos Net, P.C., Cuadro, F. and Crispo, M. (2016) Advances and limitations of in vitro embryo production in sheep and goats. Anim. Reprod., 13(3): 273-278.

7. Wataru, I., Kenichi, Y., Daisuke, S., Yuki, T., Maria Portia, B.N., Masatoshi, M., Kenichi, Y., Masashi, T. and Masaya, M. (2018) Simple separation of good quality bovine oocytes using a microfluidic device. Sci. Rep., 8(1): 14273 .

8. Piras, A.R., Blanco, I.M., Soto-Heras, S., Catala, M.G., Izquierdo, D., Bogliolo, L. and Paramio, M.T. (2019) Resveratrol supplementation during in vitro maturation improves embryo development of prepubertal goat oocytes selected by brilliant cresyl blue staining. J. Reprod. Dev., 65(2): 113-120.

9. Alcoba, D.D., Schneider, J., Arruda, L., Martiny, P.B., Capp, E., Von Eye Corleta, H. and Brum, I.S. (2017) Brilliant cresyl blue staining does not present cytotoxic effects on human luteinized follicular cells, according to gene/protein expression, as well as to cytotoxicity tests. Reprod. Biol., 17(1): 60-68.

10. Watson, A.J., De Sousa, P., Cavaney, A., Barcroft, L.C., Natale, D., Urquhart, J., Westhusin, M.E. (2000) Impact of 
bovine oocyte maturation media on oocyte transcript levels, blastocyst development, cell number, and apoptosis. Biol. Reprod., 62(2): 355-364.

11. Guler, A., Poulin, N., Mermillod, P., Terqui, M. and Cogne, Y. (2000) Effect of growth factors, EGF and IGF-I, and estradiol on in vitro maturation of sheep oocytes. Theriogenology, 54(2): 209-218.

12. Rao-Fen, Y., Xian-Rong, X. and Xiang-Dong, Z. (2019) Effect of cysteine, insulin-like growth factor-1 and epidermis growth factor during in vitro oocyte maturation and in vitro culture of yak-cattle crossbred embryos. J. Appl. Anim. Res., 47(1): 463-466.

13. Kafi, M., Nili, H. and Mesbah, F. (2005) Changes in ultrastructure/timing of in vitro maturation of camel oocytes. Adv. Reprod., 6(July): 19-24.

14. El-Harairy, M.A., Shamiah, S.M., Abdel-Khalek, W.A. (2004) Effect of pregnancy status and harvesting technique on recovery rate and categories of dromedary camel oocytes. Adv. Reprod., 7(June): 23.

15. Alm, H., Torner, H., Löhrke, B., Viergutz, T., Ghoneim, I.M. and Kanitz, W. (2005) Bovine blastocyst development rate in vitro is influenced by selection of oocytes by brilliant cresyl blue staining before IVM as indicator for glucose-6-phosphate dehydrogenase activity. Theriogenology, 63(8): 2194-2205.

16. Fathi, M. and El-Shahat, K.H. (2017) L-carnitine enhances oocyte maturation and improves in vitro development of embryos in dromedary camels (Camelus dromedarius). Theriogenology, 104(2017): 18-22.

17. Fathim M., Salama, A. and Badr, M.R. (2018) Improvement of the developmental competence of canine oocyte using caffeine supplementation during IVM at different maturation time. Zygote, 26(2): 162-167.

18. Mohamed, F., Moawad, A.R. and Badr, M.R. (2018) Production of blastocysts following in vitro maturation and fertilization of dromedary camel oocytes vitrified at the germinal vesicle stage. PLoS One, 13(3): e0194602.

19. Bhojwani, S., Alm, H., Torner, H., Kanitz, W. and Poehland, R. (2007) Selection of developmentally competent oocytes through brilliant cresyl blue stain enhances blastocyst development rate after bovine nuclear transfer. Theriogenology, 67(2): 341-345.

20. Rodriguez-Gonzalez, E., Lopez-Bejar, M., Velilla, E. and Paramio, M.T. (2002) Selection of prepubertal goat oocytes using the brilliant cresyl blue test. Theriogenology, 57(5): 1397-1409.

21. Egerszegi, I., Alm, H., Rátky, J., Heleil, B., Brüssow, K. and Torner, H. (2010) Meiotic progression, mitochondrial features and fertilization characteristics of porcine oocytes with different G6PDH activities. Reprod. Fertil. Dev., 22(5): 830-838.

22. Wang, L., Lin, J., Huang, J., Wang, J., Zhao, Y. and Chen, T. (2012) Selection of ovine oocytes by brilliant cresyl blue staining. J. Biomed. Biotechnol., 71: 161372.

23. Silva, D.S., Rodriguez, P., Galuppo, A., Arruda, N.S. and Rodrigues, J.L. (2013) Selection of bovine oocytes by brilliant cresyl blue staining: Effect on meiosis progression, organelle distribution and embryo development. Zygote, 21(3): 250-255.

24. Catalá, M.G., Roura, M., Izquierdo, D., Hammami, S., Uzbekova, B.S. and Paramio, T.M. (2012) Relative mRNA expression of 4 candidates in lamb oocytes selected by brilliant cresyl blue staining. Reprod. Fertil. Dev., 25(1): 246-246.

25. Dhanraj, N. and Purohit, G.N. (2005) Effect of epidermal growth factor on maturation and fertilization in vitro of goat follicular oocytes in a serum free or serum supplemented medium. Vet. Arhiv, 75(6): 459-467.

26. Dinesh, K. and Purohit, G.N. (2004) Effect of epidermal and insulin-like growth factor-1 on cumulus expansion, nuclear maturation and fertilization of buffalo cumulus oocyte complexes in simple serum free media DMEM and Ham's F-10. Vet. Arhiv, 74(1): 13-25.

27. Pawshe, C.H., Rao, K.B. and Totey, S.M. (1998) Effect of insulin-like growth factor I and its interaction with gonadotropins on in vitro maturation and embryonic development, cell proliferation, and biosynthetic activity of cumulus-oocyte complexes and granulosa cells in buffalo. Mol. Reprod. Dev., 49(3): 277-285.

28. Lonergan, P., Monaghan, P., Rizos, D., Boland, M.P. and Gordon, I. (1994) Effect of follicle size on bovine oocyte quality and developmental competence following maturation, fertilization, and culture in vitro. Mol. Reprod. Dev., 37(1): 48-53.

29. Harvey, M.P. and Kaye, P.L. (1992) Insulin-like growth factor-1 stimulates growth of mouse preimplantation embryos in vitro. Mol. Reprod. Dev., 31(3): 195-199.

30. Lee, E.S. and Fukui, Y. (1995) Effect of various growth factors in a defined culture medium on in vitro development of bovine embryos matured and fertilized in vitro. Theriogenology, 44(1): 71-83.

31. Simmen, R.C.M., Ko, Y. and Simmen, F.A. (1993) Insulin-like growth factors and blastocyst development. Theriogenology, 39(1): 163-175.

32. Down, S.M., Dow, M.P. and Fagbohun, C.F. (1991) The meiotic response of cumulus cell-enclosed mouse oocytes to follicle-stimulating hormone in the presence of different macromolecules. J. Exp. Zool., 258(3): 373-383. 